\title{
Impacts of Reforms in Chinese Educational System
}

\author{
Rassidy Oyeniran $^{1, *}$ \& Emile Uwamahoro ${ }^{1}$ \\ ${ }^{1}$ Faculty of Education, Beijing Normal University, Beijing, China \\ *Corresponding author: Faculty of Education, International and Comparative Education \\ Research Institution, Beijing Normal University, China, 19 Xin Jie Kou Wai Street, Beijing \\ 100875, PR China.E-mail: rassidy2006@yahoo.fr; hariel.or1@gmail.com
}

Received: December 22, 2016 Accepted: January 11, 2017 Published: February 14, 2017

doi:10.5296/ije.v9i1.10495ＵRL: https://doi.org/10.5296/ije.v9i1.10495

\begin{abstract}
This paper focuses on the impacts of the reforms in Chinese educational system. Education is part of China's overall development and it is known that the last recent decades the whole Chinese educational system has been the subject of unprecedented reforms. The increased impact of educational reforms has provided significant human resources and innovation, which facilitated progress in the economic, political, cultural, and social development. The development of China's education system has been a major factor in its economic and social growth. This article aims to examine some of the effects that the reforms have generated on the entire Chinese education system and provide guidelines for minimizing limitations and weaknesses of the education system in its reforms. Using a qualitative approach to collect the data drawn from articles and materials, this paper aims to discuss educational reforms and how they affect the Chinese education system by exploiting the readings related to the subject. Some progress has been achieved in the extent to which transformations are perceptible. Gains have been made through educational policies supported by good economic health for years. Despite the progress, education seems to be the field of some contradictions and there is a need to overcome certain shortcomings and weaknesses of educative practices that the Chinese educational system is still facing. Possible solutions are proposed in conclusion and recommendation.
\end{abstract}

Keywords: Educational system reform; quality; ' 'gaokao”; disparity; China

Acronyms and Abbreviations: RBM Result-Based Management; MOE Ministry of Education; PISA Program for International Student Assessment; OECD Organisation for Economic Co-operation and Development; GDP Gross Domestic Product. 


\section{Introduction}

Education is the most powerful weapon which you can use to change the world, said Nelson Mandela, former South African President (Duncan, 2013). Of all human activities education is among the highest and noblest ( $\mathrm{Gu}, \mathrm{Li} \&$ Wang, 2009) ensuring the harmonious structure of a nation. China is one of ancient civilization in the world and attaches great importance to education not only in modern society, but also in ancient times and it began early with Confucius (551 B.C- 4779 B.C) who regarded education as an important component of social development (Xu \& Mei, 2009). In recent decades multiple educational reforms have been instituted within mainland China.

Between 1966 and 1976 the Cultural Revolution seriously damaged China Education plunging into a deep crisis, but from 1977 to 1991 a new reform policy initiated opening to the world has become the highest priority for the reconstruction of education. Deng Xiaoping, great leader of People's Republic of China, engaged China to learn from West, in search of scientific and technical development (Yang, 2009). Thus, 1978 has been particularly important in the modern history of China, because it marked its entry into a new period of opening up reform as one of socialist modernization. The nation collectively walked along a new path of reform and development. Since 1978, the educational policy in China has experienced mainly four stages: the recovery and reconstruction of the educational order (1978-1984); the total start-up of educational system reform (1985-1992); the adjustment of educational policy facing the reform of the market economy system (1993-2002) and the new development of the educational policy under the guidance of Scientific Outlook on Development (Xu \& Mei, 2009). All these stages thrived with the aim of improving the educational system. Xu and Mei (2009) reported that the rapid development of the economy and the realization of nine-year compulsory education have provided a sufficient foundation for the further reform of education in the new century.

To enable better responses to changes in the contemporary world and the expectations of the Chinese people, Chinese education system has begun an unprecedented reform. The reform covers all aspects, from pre-school education to continuing education, including educational objectives, the role of teachers and researchers and international cooperation. Thus, China's education system has steadily improved from primary education, secondary and higher education, and adult education. It is clear that until now several reforms have undoubtedly helped to modernize the Chinese education system. This study seeks to analyse some of these reforms and examine the extent to which these reforms were implemented, their associated challenges and their implications on the quality of education as well in the most populous country over the world.

\section{Literature Review}

\subsection{Significance of the Reforms and Modernization of Education}

To ensure real importance of education China has adopted several laws, rules and administrative regulations which constitute the basic framework of the Chinese educational 
system. The objective of reforming the education system shall initially establish an education system geared to the system of socialist market economy, the political system as well as the technological system. Only in this way would it be possible to achieve an active and vivid development of the economy and society, and to carry out the new way of educational development (Xu \& Mei, 2009)

Moreover, the article 19 of the 1982 Constitution (Constitution of the People's Republic of China, 1983) stipulates that "the state develops socialist education to raise the cultural and scientific level of the whole people." Several laws aimed to revitalizing the country through science and education complete it and remind that education is at the service of socialist modernization and aims to build a socialist society advanced culturally and ideologically and materially (Grenié \& Belotel-Grenié, 2006). According to these authors, Education based on the principles of Marxism-Leninism Mao Zedong thought and the theory of building socialism with Chinese characteristics. Therefore, the ideological and political training of youth is omnipresent at every stage of the educational background and framed by laws and regulations from the reforms.

Educational system is the basic educational organization form in a country and the reform of educational system is the key element in educational reform. To be modernized, any educational system must be adapted to the economic, political and cultural development. The economic boom of the 1980s has enabled China to adapt and develop its education system based on reforms that reflect the social values of the country, and political and economic realities. Since China has attached great importance to quality of education, efforts are made to maintain and protect the educational rights of disadvantaged groups. Developing education in western areas and helping poor students are two notable examples (Xu \& Mei, 2009).

When the economic system in a country changes, the educational system will also change eventually (Yang, 2009) and the reform of educational system can be beneficial to the reform of economic system (Wang, 1989 as cited in Yang, 2009). On 27 May, 1985, decision on Reform of Educational System was issued by the Central Committee of the Chinese Communist Party (CCP) and in 1993 Program of China's Educational Reform and Development was issued by the Central Committee of the CCP and the State Council (He, 1998 as cited in Yang, 2009). The goal of the reforms was to enhance national competence and provide more and better manpower adapting to the reform of socialist market oriented economic and political system, and to the scientific and technological development (Yang, 2009). Since 1978, throughout the period of reform and opening up, China implemented a nine-year compulsory education system, an academic degree system, a graduate education system, and has further improved the adult education system.

The objectives of the Chinese education system were clearly and primarily to focus on learning training, a curriculum structure adapted to meet the diverse needs of students, a selection of knowledge and skills essential for lifelong learning. However, it is more advantageous for young people to receive training adapted to the changing global economy and globalization, in order to give the youth better chances of employability. In this perspective, for example the China's national exams, known as gaokao, could be reformed to 
hatch and encourage more talents. Hilton (2016) reported that in some provinces of China some educators wish to see even greater changes in the gaokao system with more diversified university entrance channels.

Gaokao has served as the main canal for getting ahead in Chinese society since the 10th century, and nowadays prepare students for joining best Chinese universities. According to Hilton most of Chinese people, especially the scholars and educators criticize gaokao system arguing that education reforms will never be successful unless criteria other than the rote-learning-focused gaokao are used in university admission. Yet the question will be how to preserve quality in the world's largest educational system when we know that the Chinese government wants to observe prudence in the reform of gaokao, which is the only opportunity for many students to climb social scale by moving to the best universities. Obviously challenges remain despite numerous efforts that Chinese government has already made. In Asian societies, these college entrance exams are still considered by most students and their parents as the only gateway to a successful life.

\subsection{Compulsory Education and Massification}

In 1986, China promulgated the Compulsory Education Law, putting forward the implementation of nine years of compulsory education. Compulsory education is implemented nationwide in accordance with the Compulsory Education Law, which stipulates that all school-age children and adolescents must receive education that is free, mandatory, and universal.

China's nine-year compulsory education is composed of primary and junior secondary education. The following figure shows the Chinese educational structure as it exists currently (Figure 1).

School-age children and adolescents are exempted from entrance examinations. Any child who is at least 6 years must undergo compulsory education of nine years. Local governments are responsible, under the control of central authorities of this training period free. After the establishment of compulsory education system in China in 1986 and the introduction of monitoring system for the development of compulsory and literacy education in 1993, great progress had been made in the quantitative development of compulsory education before the end of the 20th century (Wang, 2009).

In 1995 a huge effort was launched to increase enrolment rates in secondary and higher education. The reform had a number of objectives: to generalize compulsory education for nine years (currently, only three quarters of an age group after 9 years of schooling); remove illiteracy; develop technical secondary education, adult education and continuing education; improve the level of education of girls, and of national minorities in poor areas; renovate and construct buildings for research and teaching in order to increase the carrying capacity of the students. In 2007 the coverage population of compulsory education and literacy education reached 98\% (MoE, 2007). 


\section{China's Educational Structure}

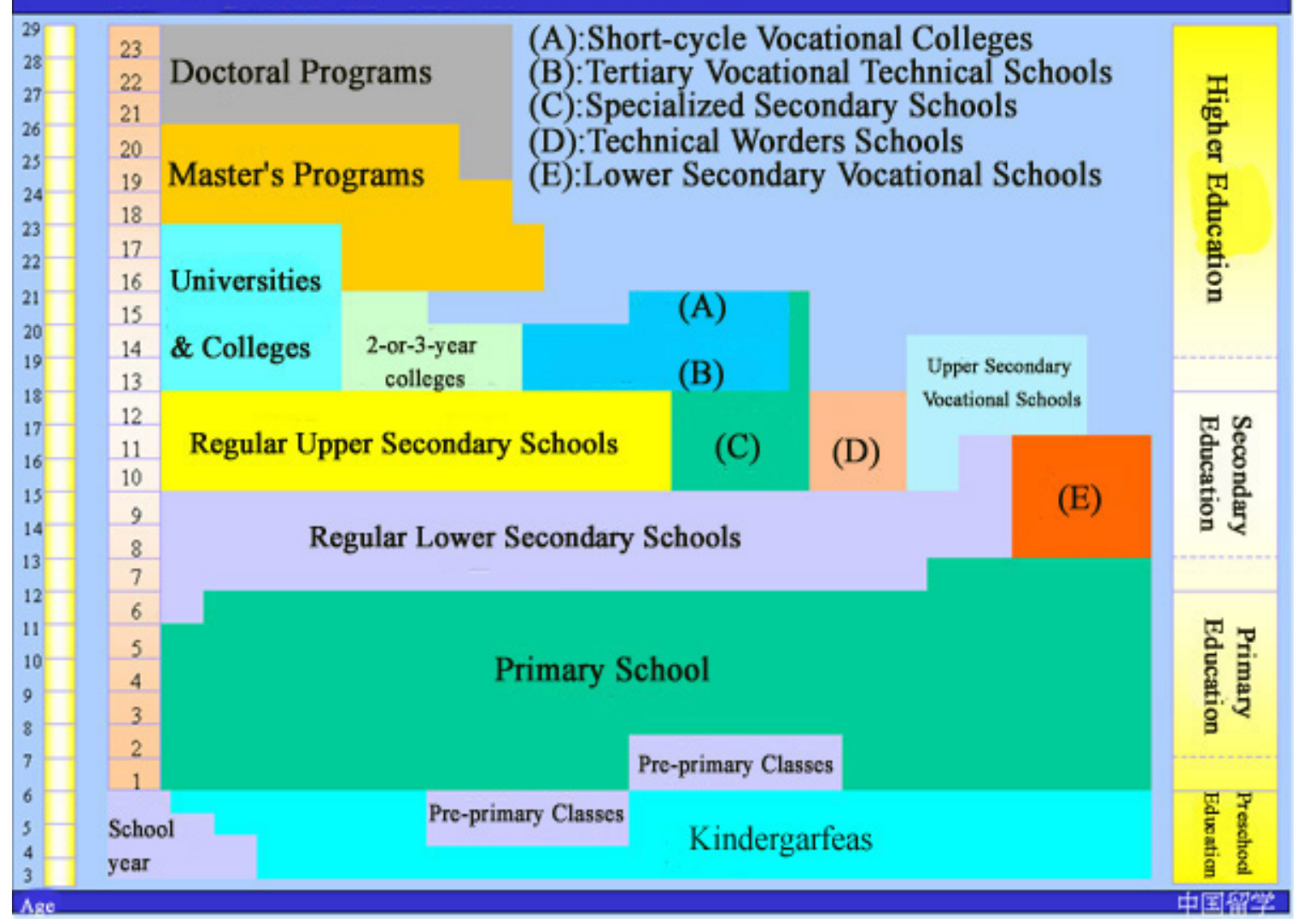

Figure 1: China's Educational Structure

Ministry of Education indicated that, in 2011, the enrolment rate of primary school age children across the nation was $99.76 \%$ while the gross enrolment rates of junior high was $100.1 \%$ and senior high schools was and $84.5 \%$ and that of preschool children aged 3 to 5 was $62.3 \%$ (MOE, 2012a). Vocational education is also an important part of China's educational system and a crucial means of promoting socioeconomic development and employment. The vocational schools were also given due attention during the course of reforms. In 2010, 50.94\% of senior high school students were enrolled in secondary vocational schools and students enrolled in all forms of higher vocational colleges accounted for $46.92 \%$ of the total number of students enrolled in higher education (Statistical Bulletin for National Educational Development, 2010).

The universal level of compulsory education has been rapidly enhanced since the promulgation of the Compulsory Education Law in 1986. By the end of 2011, China has largely succeeded in achieving the goal of "Universal Nine-year Compulsory Education" nationwide with the enrolment ratio reaching $100 \%$ (MoE, 2013). According to Ministry of Education the gross enrollment rate in junior middle schools had reached $100.1 \%(\mathrm{MoE}$, 2012a).

The number of high school new enrolled students in China up to 2014 was 14, 48 million for junior high school, and : 7,97 million for senior high school (Statista, n.d). According to the 


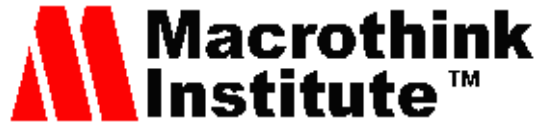

World Bank Group (2014) the gross enrolment ratio in secondary for both sexes was $94 \%$ in 2014, while in the same year the number of students enrolled in Higher Education was about 35, 59 million for 2845 Higher Education Institutions (Michael, 2016). By 2013, 100\% localities at the county level achieved the goal of universalizing 9-year compulsory education; by 2015 , gross enrolment rate in higher education was 36\% (Sang, 2015).

Under China's Law on Nine-Year Compulsory Education, primary and middle school is tuition-free. However, a small tuition fee is requested from students after the compulsory nine years of education during high school. Under this circumstance it would be hard for some poor families to meet the cost of education given their weak economy, especially for parents who live in the rural area. Despite the efforts for universal education, there are still equity issues and barriers that may discourage some parents to send their kids to school. The following pictures show an overview of school attendance in city and village as well under Nine-Year Compulsory Education (see Ph1 \& Ph2)

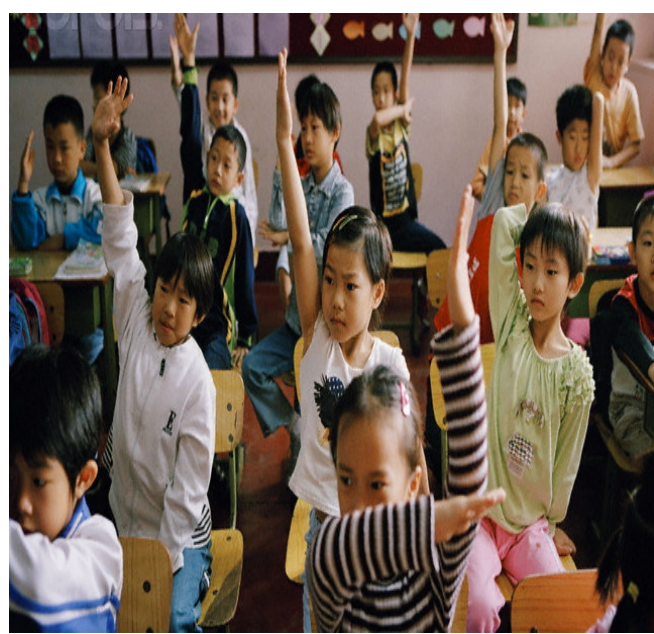

Ph1: Primary school students in Guizhou Source: http://asiasociety.org/blog/asia/ challenges-bringing-global-education-china

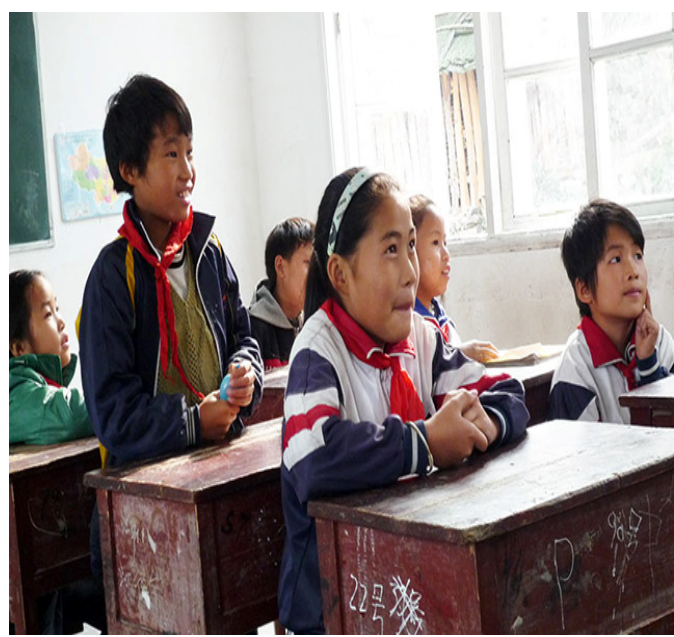

Ph2: Primary school in a City

Source: China's Ministry of Education

\subsection{Curriculum}

China's current school education system consists of four levels: preschool, elementary, secondary, and higher education. In the course of the reforms, the curriculum was also affected since it is an important aspect in the educational structure. Curriculum is a total package of learning activities designed to achieve the objectives of the training programme. It designs the content, structure and sequence; and the methods of training as well. Basically, its aim is to ensure learners acquire some competencies (skills, knowledge and ability). Also, it is universally used in the framework of theory of pedagogy and sociology of education (Braslavsky, 2012).

In 1999, State Council issued decision on deepening educational reform and promoting quality education in an all-round way and a fairly complete modern curriculum system has been operating in China at the end of the 20th century (Xu \& Mei, 2009). New curriculum 


\section{Macrothink}

International Journal of Education

ISSN 1948-5476

2017, Vol. 9, No. 1

reform was a successful part of the quality education, and contributed a great deal to the political, economic and cultural development. The principal aims of basic education curriculum are to develop the spirit of patriotism, collectivism and promotion of socialist awareness and national cultural tradition to democratic awareness, respect to national laws and public morals, to cultivation of good values and attitudes of the students towards the world and life, and also to enhance flexibility of school curriculum (MoE, 2001). The new reform of the 1999 curriculum takes into account the individual development and promotes the creation of comprehensive practical activities based on direct experience of students, integrating theoretical knowledge in social life (Wang, 2014).

The development of school curriculum is one of the most important dimensions in the quality provision of basic education (Wang, 2009), this is why a system called three-level management is stated in outlines of the reforms of basic education curriculum issued by the Ministry of Education in July 2001. In this document Basic education and high secondary school each has a structured curriculum for each level of education. The main subjects in curriculum of basic education and senior high school includes math, Chinese, Foreign languages, science, physical education, comprehensive practical activities and humanities and social sciences.

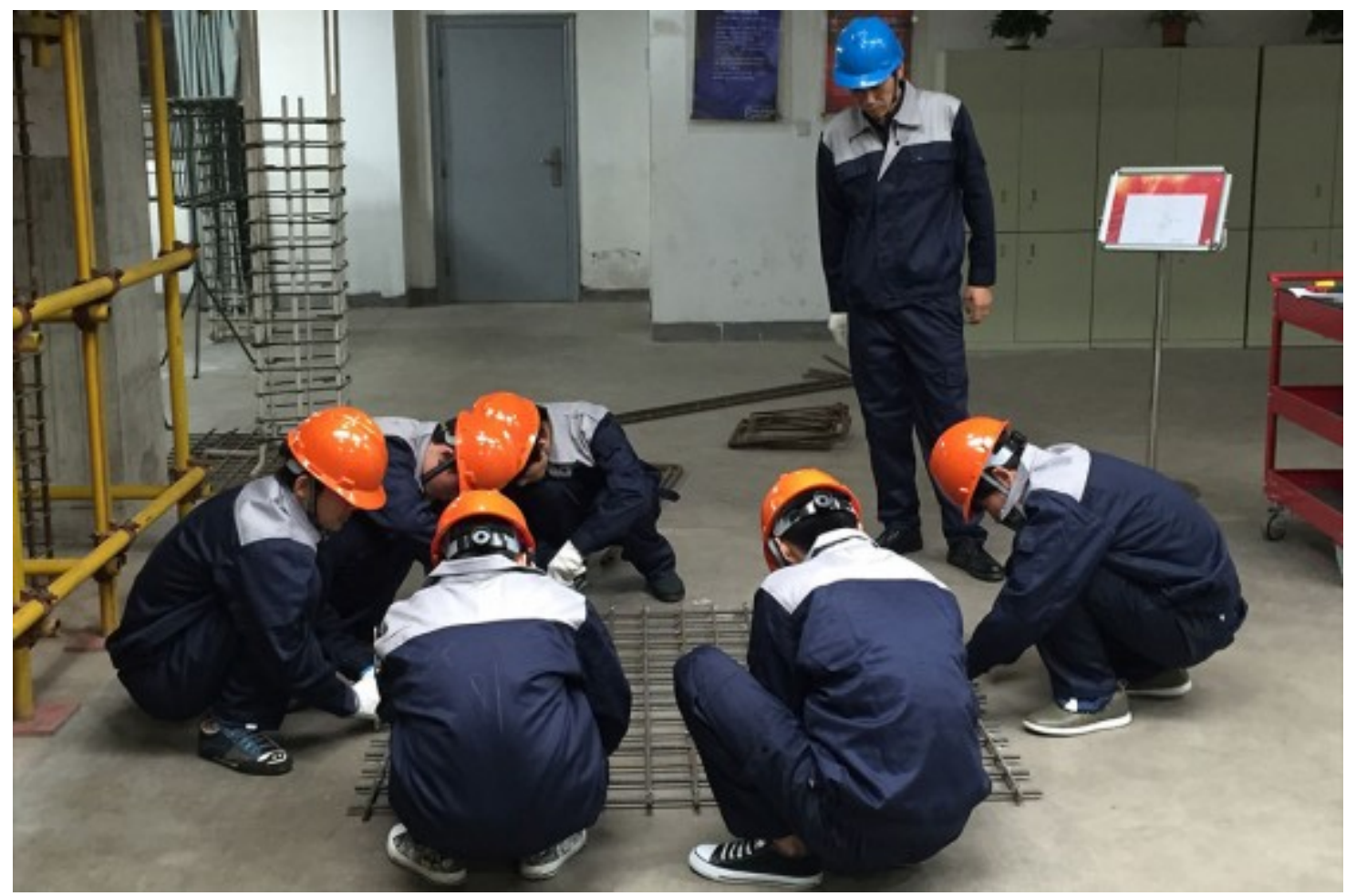

Ph3: Students at the school of the Shanghai Construction Group (Vocational School)

Source: Heather Singmaster/Asia Society

(http://asiasociety.org/blog/asia/challenges-bringing-global-education-china)

China's vocational and technical education system faced problems as many of China's vocational schools have had a narrow curriculum, relatively weak connections to industry, and lower funding than academic education (Stewart, 2017). But in recent years, as 
underlined by Stewart (ibid), China is making a huge investment in vocational education, adopting a series of measures to greatly expand vocational education and training schools and improve its quality $(\mathrm{Ph} 3)$.

\section{Method}

In this paper the qualitative approach was used. The objective of this study is to examine the impact of reforms on the educational system. The analysis was based primarily on documentary research on Chinese educational system. Document analysis is a systematic procedure for reviewing or evaluating documents-both printed and electronic (computer-based and Internet-transmitted) material (Bowen, 2009, Muchielli 1991; Bardin, 2003).

The data were collected mainly from secondary sources such as books, articles, and government websites and accounts of documents were systematically extracted from materials like Chinese Ministry of education manuals; background papers; books and brochures; journals; newspapers articles; organisational or institutional reports; survey data; Non-periodical Web Document, International Organisations Reports. The objective of this study was to explore current educational reforms and their impact on Chinese educational system. These data were used to explore the link between reforms and the quality of the Chinese education system

\section{Findings and Discussion}

\subsection{Consequences of the "Culture of Result" in Chinese Education}

The culture of result is a kind of measurement of results which is not an isolated activity. It is incorporated in the process of measuring results that starts with the design of a policy, reforms and evolves over time. Different results-measurement activities occur at different points in time, but always as part of the ongoing management of a policy, program or initiative (Treasury Board Secretariat, 2001).

The culture of results is mostly embodied within the Result-Based Management (RBM).
"RBM is a management strategy by which all actors, contributing directly or indirectly to achieving a set of results, ensure that their processes, products and services contribute to the achievement of desired results (outputs, outcomes and higher level goals or impact). The actors in turn use information and evidence on actual results to inform decision making on the design, resourcing and delivery of programmes and activities as well as for accountability and reporting" (United Nation Development Group, 2011, p. 2)

Basically, the strategy consists of producing outcomes that may be a physical output, a change, an impact or a contribution to a higher level goal that used for accountability, reporting and to feedback into the design, resourcing and delivery of projects and operational 
activities. It focuses on implementing performance measurement, learning, and adapting, as well as reporting performance. This is a guide to assist managers and evaluation specialists in establishing a foundation to support a strong commitment to results, a prime responsibility of public service managers (Treasury Board Secretariat, 2001).

The culture of results (result-based management) in the Chinese education system has a national reputation, even internationally to access higher education. Yet this practice is not without consequences for students and parents as well as the efficiency of the education system. Speaking of "Gaokao", national review of access to higher education, Mao Zedong himself had recognized the stressful nature of this practice and declared (Wang, 2014):

School classes are too heavy, they are hurting young people who are in daily tension. Courses can be halved. It is inappropriate that students read every day, they could participate in productive work and social activities. The current methods of examinations, with strange questions, and the surprise are baffling like strategies used in front of the enemy (Wang, 2014).

The current reform of gaokao carries both the content of the tests and the modernization of the registration system for future students. In its original form, the gaokao consists of three basic tests: Chinese, mathematics, English. To recruit their future students, universities refer exclusively to the note obtained gaokao. Competition for access to higher education is severe (Wang, 2014, p.3).

In the last years of secondary school, students focus their efforts on the preparation of entrance exams to university, the "gaokao". Failure to gaokao means upheaval in the future prospects of young Chinese (Embassy of the People's Republic of China in French republic, 2015). Furthermore, the one-child policy has intensified stress and psychological pressure of parents and their children for every family wants their child to become a genius. Also, as pointed out Wang (2014), the elite schools are created and searched and parents seek by all means to make admit their children. While the gap between good schools and mainstream schools is widening, industrialization and commercialization of education have developed quietly, as in Beijing where costs related to school choice can reach 60000 yuan, 5000 euros (Wang, 2014). Thus the social and professional future of young Chinese people depends largely on their school and university curricula. Although, in 1999 the term 'qualifying education' (zhijiaoyu) has replaced "teaching to the test" (yingshijiaoyu) difficulties exist and merely reflect school and social inequalities (ibid: 3 ).

During the last three decades of education reforms, policies concerning the reduction of burden on school students and improving the quality of education have been introduced but have not yet obtained satisfactory results. The ideology of work by the culture of the result is the one that defined the current situation in China and maintains a cultural difference between the young. Admission to gaokao priced miles intellectual and physical effort seems to give young people a chance of social success, but education based on hard work and absolute search for performance may harm the personal interests and above all destroy the spirit innovation (Wang, 2014). Also the first values of education as such as socialization, humanization, morals and ethics are likely to be less important for young people who have 


\section{$\triangle$ Macrothink}

International Journal of Education

ISSN 1948-5476

2017, Vol. 9, No. 1

yet needs of these prerequisites to be in line with the concept of socialist harmonious society (Grenié \& Belotel-Grenié, 2006) and the need to promote morality among the people. A good education was not just one that would give us knowledge and prepare us for a vocation, it was also an education that would encourage an ongoing commitment to social justice, particularly to the struggle for racial equality (hooks, 2010, p.1).

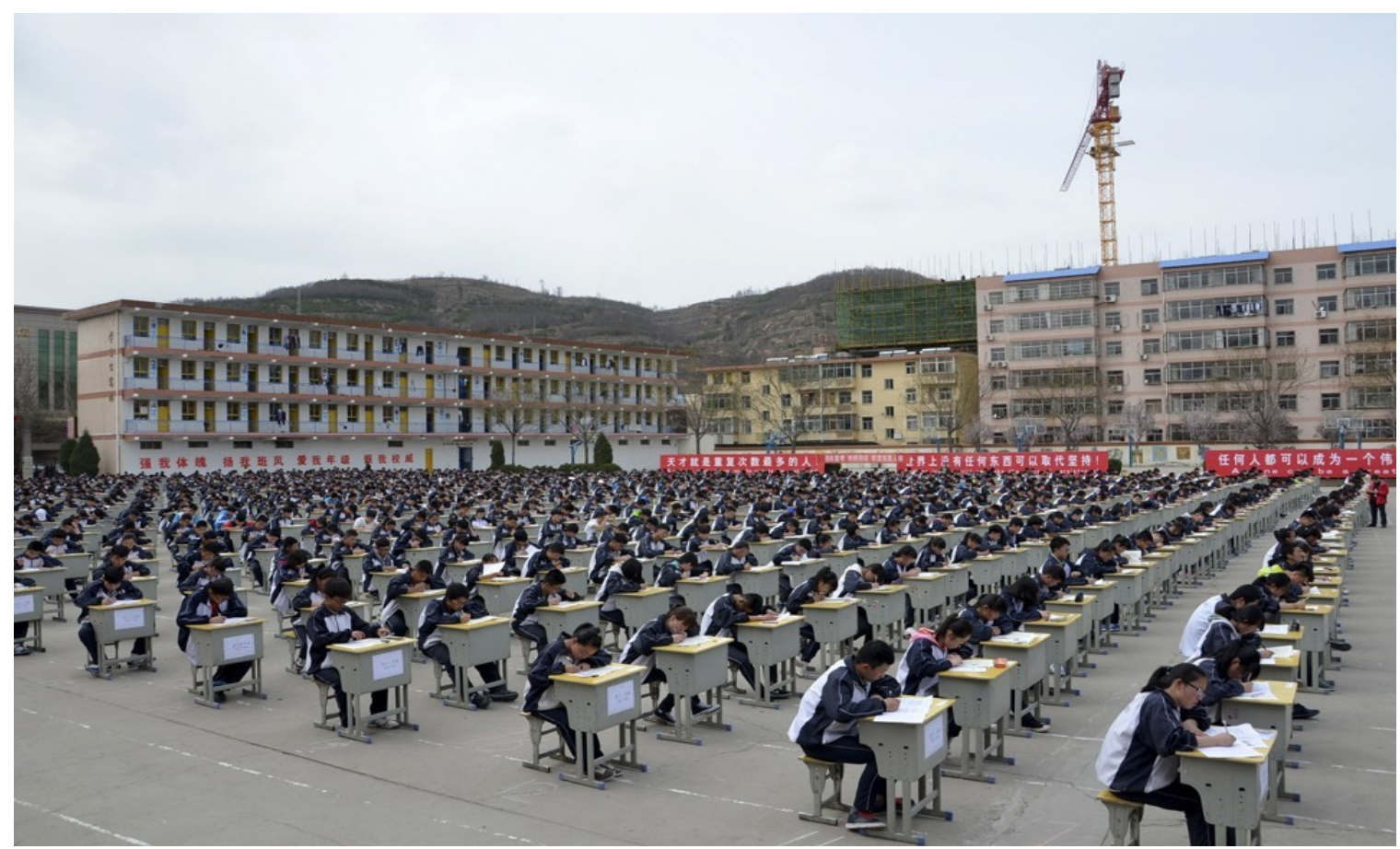

Ph4: An overview of "gaokao" exam in China

Source:http://asiasociety.org/global-cities-education-network/chinese-innovations-career-and -technical-education

In China, there are different provinces (especially in the West regions) and schools that experience inequality putting at the risks students from those areas and minorities to access schools and Higher Education or pass the "gaokao". As said Gao (2014) a huge gap in educational opportunities between students from rural areas and those from cities is one of the main culprits. Gao further noted that some 60 million students in rural schools are "left-behind" children, cared for by their grandparents as their parents seek work in faraway cities. While many of their urban peers attend schools equipped with state-of-the-art facilities and well-trained teachers, rural students often huddle in decrepit school buildings and struggle to grasp advanced subjects such as English and chemistry amid a dearth of qualified instructors (Gao, 2014). We argue that this unlikely give rural students no chance when competing academically with their urban counterparts and lead them to stand virtually. As a result, most children and young people from poor areas, hometown village in central and West China left-behind because of that practice.

On June 2016, there were 9, 4 million students taking the National Higher Education Entrance Examination (Gao Kao) in China (see Ph4). Investment in education accounts for about 4\% of total GDP in China. China Education Center Ltd. (n.d). 


\subsection{Contrasts or Paradoxes within the Education System}

There are some contrasts in gearing education, equity, assessment and qualifications. "Gearing education to the needs of modernization, the world and the future" was a vision of Deng Xiaoping that was to adapt education to the needs of modern society to obtain as quickly as possible the elite in terms of human resources able to boost economic and social growth ( Xu \& Mei, 2009). But this education policy was based on elitism with the National College Entrance Examination. Xu \& Mei (2009) pointed out that it places emphasis on selection and excellence, but neglects that basic education is a public good; it overstresses the importance of knowledge learning, and the students do not develop in an all-round way.

Despite many efforts, the issue of equity remains mostly within ethical minorities and in rural areas. According to the authorities, in 2004 are nearly 2.3 million children who are out of school, of which $70 \%$ girls and the dropout rate in rural areas is $2.45 \%$ for primary and $3.91 \%$ for college (Shangwu, 2006). Moreover there is insufficient coaching and educational management and a lack of interest in training whose content is often poor (Grenié \& Belotel-Grenié, 2006). Teachers in rural areas are less well trained and paid less than those in urban areas: in 2001, the proportion of teachers with higher education was in town to $40.94 \%$ for the primary and $23.51 \%$ for college, while in rural areas it was $20.25 \%$ and $9.35 \%$ (Yixian \& Yanshu, 2004).

In spite of the compulsory education law which requires all six-years-olds to enrol in nine years of compulsory education regardless gender, ethnicity or race, significant inequalities remain (Peng, McNess, Thomas, RongWu, Zhang, Li, \& Tian, 2014). In addition, curriculum reform and classroom practice was attempting to move Chinese society away from an over whelming and deep seated emphasis on examination results towards the facilitation of all round development and lifelong learning, although so far with some evidence of limited success ( Thomas et al., 2012 as cited in Peng et al., 2014).

Moreover many families are in debt to finance the high school or university of their offspring. With the massification of flows, obtaining a first job often requires the acceptance of underpaid situation where the youth is over graduated. Given the depreciation of their qualifications on the labor market and competition with migrants, many young people have a sense of frustration and are disappointed that personal relationships and social background remain crucial to find a place (Heckman \& Yi, 2012; Heckman, 2003; 2005). If this situation persists, it would not encourage investing in human capital. Besides, Grenié \& Belotel-Grenié (2006) pointed out the imbalance of the reforms : while there was massification but unequal access by social status of families and their residence there, the requirement of success individual is, at heart, contrary to socialist slogans under which the collective takes precedence over the individual, educational resources are more abundant in developed or urbanized coastal regions while the western rural areas are disadvantaged, the openness to Western education more learner-centered, while the specialties of the Confucian heritage are claimed.

The current reality is that West and North-West China have no enough resources and school infrastructures as the other regions. These zones are mostly rural areas. Currently rural and 


\section{Macrothink}

urban students face an ever-widening gap in the access and quality of their respective education (see Ph5 \& Ph6).

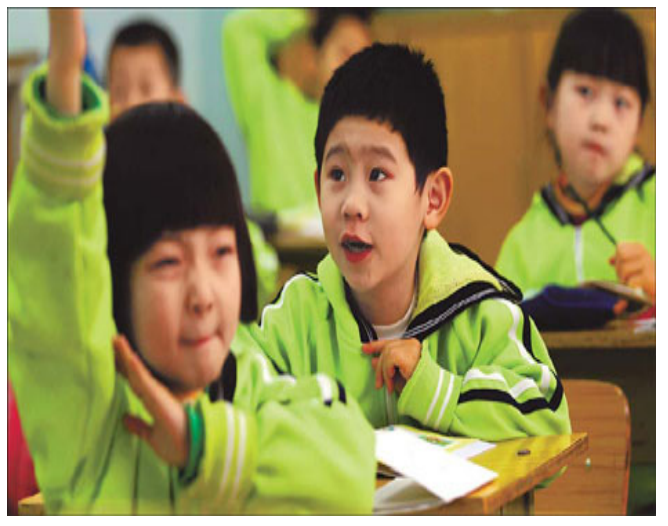

Ph5. Pre-school in urban area

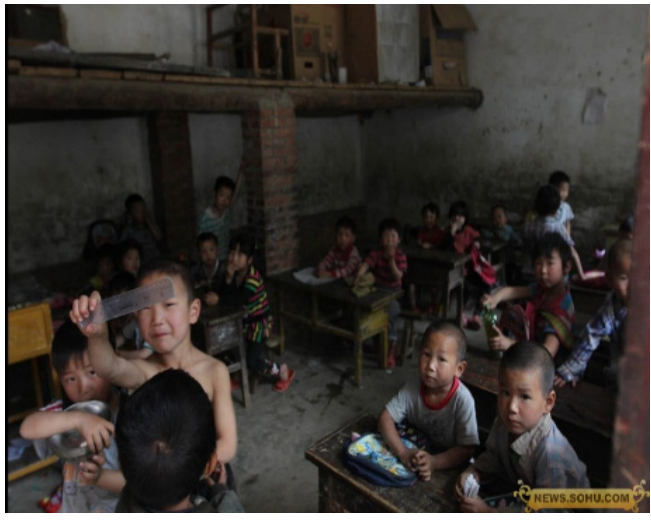

Ph6. Pre-school in rural area

Source: www.newyorker.com/magazine/2004/04/05/kindergarden-2

Nearly a million rural, primary school-aged children drop out of education system every year, while urban children don't face the kinds of problems that would encourage dropping out (Collins, 2016). That is the ongoing situation mostly in West and North-West of China where the low investment in poor and rural schooling almost invariably leads to exclusively children from rich families to continue to higher education (Collins, 2016).

The reforms reflect a trend in China with regard to its educational system and the number of people who actually benefit from it (Collins, 2016). However, challenges still remain due to lack of funding that is a main focus and other socio-economic issues. In fact, in urban areas almost all children attend school but the school fee and tuition are very expensive. For example in Beijing reputable schools tuition is at least $1000 \mathrm{RMB} /$ month (170 USD). In the rural areas: $2 / 3$ out of 90 million children ( $0-6$ years old) $50 \%$ attendance ( $20 \%$ in the poorest parts of the country). While China shifts into a major and influential world power, China still has a massive urban-rural divide in terms of education quality. Now it's time to devise ways to reach those in rural areas in the provisional of universal and quality education.

Even if governmental officials have announced that the reforms of the country's education system will positively affect millions in Chinese adult education (Hilton, 2016) these reforms are not easy given the nation's challenges. China is where the largest human migration in world history is taking place: some 300 million people are moving from rural areas to urban centers in search of better economic opportunities (Collins, 2016). According UNESCO (2016), 56\% of urban population growth between 2000 and 2010 was a result of rural to urban migration despite strong disincentives such as rural residents being prevented access to education and health benefits once in cities.

Another paradox is focus on PISA and Gaokao examination in teaching and learning in Chinese educational system. PISA 2012 (The Programme for International Student Assessment (PISA): a study that tests scholastic performance by 15 -year-old students around the world) revealed Shanghai Municipality topped the results with 613 points, well above the 
average (494 points) of the 34 Organisation for Economic Co-operation and Development (OECD) countries, an advance of nearly three years of study in mathematics over the average, more than a year and a half in reading, and more than three quarters in science (Wang, 2014).

PISA defines "global competence as the capacity to examine global and intercultural issues, to take multiple perspectives, to engage in open, appropriate, and effective interactions with people from different cultures and to act for collective well-being and sustainable development." (Hilton, 2016). This is to allow develop the competences, skills, good attitudes and values in the students that enable them to become globally competent and knowledgeable and to become global citizens.

Although Shanghai is the most developed city and more modernized (ibid), it is difficult to understand that it can represent the level of the whole China. Do these results show the real value of students' level who certainly have been prepared specifically for PISA assessment? We argue that this cannot and doesn't reflect the tangible level of students and focuses on only three or four disciplines (i.e mathematics, physics, biology, and reading). Yet subjects such as Arts, music, theater are just as important in educating children because there are among them those who certainly have talents in those disciplines that need to hatch. By not integrating these disciplines, students are not given enough opportunity and chances to master them and diversify their knowledge. As the world becomes progressively globalized it is becoming more significant for people especially students to learn abilities and skills that help them to interact across cultures and thrive in a global economy and events. These trends lead to be more prepared for involving in global skill and competence. Fortunately, as mentioned Hilton (2016) the PISA has recognized and enlarged the disciplines by including global competence assessment in its next round of testing in 2018.

Though china has other type of examination and assessment of students at national, provincial and school levels, there seems to be pressure on schools, teachers and parents of preparing students in subjects that are examined in either PISA or Gaokao. In this regard Chinese students had limited opportunity to be tested beyond these subjects

\subsection{Some Challenges in Higher Education}

Like basic education, numerous reforms failed to address difficulties and problems that exist in higher education (HE) development process as there are some inadequate resources and issues of ability for cultivating the top-notch innovative talents is still quite weak. In fact, the graduates are criticized for lack of innovation, practical ability and social responsibility. The academic program cannot meet the needs of the society because of the disconnection at time between curriculum and the realities of the labor market and the social context. For example the reforms do not often take into account the shortage in agriculture, forestry, water conservancy, geology, mineralogy, nucleus science, oil science, and so forth (Sang, 2015) despite the homogeneity of colleges and universities: 481 colleges and universities have graduate education programs.

Though employment competition pressure for graduates has been increasing after higher education expansion there is over $30 \%$ (more than a million) graduate cannot find jobs at the 
end of the study. Since 2009, 2305 colleges and universities all want to become research universities and start master and doctoral programs. Yet the conditions for sustainable development of higher education are neither adequate nor stable. Many colleges and universities are in debt: 250 billion debts in total (Sang, 2015). The policy trend of higher education reforms in the next decade hardly try to improve the quality of talents training comprehensively. However, regarding the leading economic position of China adequate measures would build a new mechanism of cooperation in education among universities, research institutes, industries, and enterprises to guarantee practical experiences of the students. Otherwise the matter is how to reform the curriculum and teaching methods, with an emphasis on research-based methods. This is an issue that imperatively requires funding supported by good educational policy management.

\subsection{Financing of Education: Insufficient Funding}

Investment in human capital and involvement in education has taken center stage in strategies to promote economic prosperity. The level of education is not only essential to the economic well-being of individuals but also to that of nations. Yet many developing countries are struggling with the cost of extending opportunities for access to higher education levels. In China real efforts have been made as noted by the China Development Bank (CDB, 2015). But public funding of compulsory education was introduced gradually, as taxes and other reforms increased the amount available. To meet the financial needs, local governments have initially sought the support of communities and their financial contributions, particularly for disadvantaged students. In 2008 government spending on education is about $3.5 \%$ of GDP for China and 4. $5 \%$ of GDP for Hong Kong (KPMG, 2010). Between 2011 and 2015 the Central Government spent 50 billion RMB investment expansion of pre-school education in rural areas (Sang, 2015).

Vocational education is also a strategic priority. We note in 2014, 11900 secondary vocational education institutions formed 18.03 million students and represented $44 \%$ of overall admissions rate in secondary schools; 1327 higher professional education institutions have formed 10.07 million students and represented $46 \%$ of the overall admission rate in higher education institutions ( CDB, 2015 ). However, funding for studies is a tax budget for the state and for families. Faced with public funding of primary and secondary education notoriously inadequate, the priority given to higher education seems questionable (National Bureau of Statistics of China, 2004). According to Grenier \& Belotel-Grenié (2006), decentralization of education funding has only increased regional disparities: three quarters are illiterate in rural areas and $72.7 \%$ of them are women, according to the 2000 census.

Despite the good economic and financial growth of China, the educational realities have certain difficulties. Indeed, there is limited funding from local government, limited professional training opportunities for teachers. Also most of small villages have no kindergartens or the schools are far from the villages. Parents have to send their children in cities for good schools. All these weaknesses are mainly due to the shortage of financing that maintain Chinese educational system challenged 


\subsection{The Issue of Privatization of Education}

Although significant progress has been made in education, it requires large financial resources from both the government and the people. Mobilize adequate resources for education in a country like China, the most populous country in the world, remains a daunting challenge. The challenges of education funding are intertwined with those of the transient public finance system in China (Wang, 2005) while the Chinese government accelerated its efforts to increase Western schools funding levels, but collected royalties increased the financial burden of rural citizens and became a central concern among the dynamics of poverty reduction and rural development in the western regions advocated by the Chinese Government. Thus, the situation in financing education has become particularly complex and, as noted Tri (2001), the private sector that has emerged has resulted in an all-out privatization, to the point that it is sometimes hard to draw a line clear and sharp demarcation between public and private sectors as they are closely intertwined. The State wants to offload its share of the financial burden of education without renouncing to exercise control, including on the programs, and impose its rules. In Article 25, the Law on Education of the People's Republic of China from March 18, 1995 stipulates that the State encourages businesses, communities and other social institutions as well as individual citizens to establish schools and other educational institutions in accordance with the law.

The funding of education is a concern for parents as it weighs more and more heavily in China. An average wage has little meaning because there are no reliable statistics on the subject, then the fact that the differences are very important between the lowest and highest income (only in the cities, a few hundred yuan to several thousand yuan) (Tri, 2001). Moreover, this gives rise to the extra work of research practice (eg, public teachers who supplement their income by working in the private). The consequence is that the quality of education is a major obstacle that determines the development of rural education.

\section{Conclusion and Recommendations}

Certainly, huge efforts have been made by the authorities for decades to raise the level of education in China. Reports from the China Development Bank (CDB, 2015) has confirmed the educational progress by mentioning that after introducing a new compulsory curriculum in 1986 , the country reached an enrolment rate of $100 \%$ in 2011 , while literacy was reduced to $1.08 \%$ in adults. Though progress has been made in the education there are still some difficulties in Chinese education. In this area, there are many problems like inequality, limited funding and high cost of education for the poor. These are the real challenges and issues of the Chinese education system.

Faced new socio-economic issues that require globalization, China should invest more in its education system to make it more productive and meet the ever-growing needs of its population. In addition, it is necessary to follow up the monitoring and the evaluation of compulsory education to ensure that all areas are covered, particularly in the west. The education program must take account of ethnic minorities and migrants and give them the 
same educational opportunities as other groups.

In higher education, it is necessary to strengthen the modernization of the higher education system through adequate funding, effective administration and autonomy to meet Chinese needs as well responding to global trends and demand. There is a need to develop a dynamic mechanism of educational cooperation between universities, research institutes, industry and business to prepare students for the socio-professional life.

Moreover the State should support the poorest people in taking charge of students with repayable grants from the earliest years of work as is done in other countries such as Canada (Quebec). Also, it would encourage private initiative in a formal and regulatory framework by providing graduates repayable funds.

Funding of education is one of the important aspects of reform. According to Sang (2015) Chinese investment in education is $4 \%$ of GDP. This investment is low therefore there is need to increase funding to address these challenges and problems faced by Chinese education system and make on going reforms successful at all levels of education,

\section{References}

Bardin, L. (2003). Content analysis. Paris: PUF.

China Development Bank (CDB). (2015, November). La chine a misé sur l'éducation et la formation professionnelle pour développer les compétences. Rapports de la Banque chinoise de développement (CDB). Experience with China's Literacy and Compulsory Education et Experience with the Development of Vocational Education in China. Retrieved from http://www.worldbank.org/content/dam/Worldbank/Event/Africa/Investing\%20in\%20Af rica $\% 20$ Forum/2015/investing-in-africa-forum-education-and-vocational-training-for-sk ills-development-in-china-fr.pdf

China Education Center Ltd. (n.d). China education. Retrieved from http://www.chinaeducenter.com/en/cedu.php

Collins, J. (2016). Positive Changes for Chinese Adult Education. BORGEN Magazine, (November 25, 2016). GLOBAL EDUCATION. Retrieved from

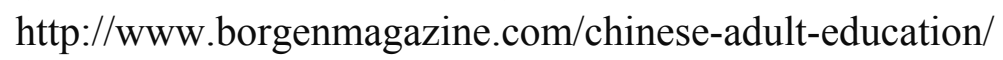

Duncan, A. (2013, April 23). Education: The Most Powerful Weapon for Changing the World. United States Agency International Development (USAID). From the American People. Retrieved from https://blog.usaid.gov/2013/04/education-the-most-powerful-weapon/

Embassy of the People's Republic of China in French republic (2015, November). Le Système éducatif chinois. La Chine au présent. Retrieved from http://www.amb-chine.fr

Explorable.com (2008, March 15). Research methodology. Popular Pages. Retrieved from https://explorable.com/fr/methodologie-de-recherche 
Gao, H. (2014, September 4). China's Education Gap. The New York Times. Retrieved from https://www.nytimes.com/2014/09/05/opinion/sunday/chinas-education-gap.html?_r=0

Gaudreau, L. (2011). Guide pratique pour créer et évaluer une recherche scientifique en éducation Montréal. Québec: Guérin-Éditeur.

Grenié, M., \& Belotel-Grenié, A. (2006). Education in China in the Era of Reform. Transcontinentales, 3, 67-85.

Gu, J., Li, X., \& Wang, L. (2009). Higher Education in China. China: Zhejiang University Press.

Heckman, J. J. (2003). China's investment in human capital. Economic Development and Cultural Change, 51, 795-804. http:// dx.doi.org/10.1086/378050

Heckman. J. J., \& Yi, J. (2012). Human Capital, Economic Growth, and Inequality in China. IZA DP No. 6550. Retrieved from http://repec.iza.org/dp6550.pdf

Heckman. J. J. (2005). China's human capital investment. China Economic Review, 16, 50-70. http:// dx.doi.org/10.1016/j.chieco.2004.06.012

Hilton, A. (2016). The Challenges in Bringing Global Education to China. Asia Society Retrieved from $\mathrm{http}$ //asiasociety.org/blog/asia/challenges-bringing-global-education-china.

Hooks, B. (2010). Thinking Critical Thinking. Routledge Taylor \& Francis Group. New York and Lodon.

KPMG (2010, October). Education in China. Infrastructure, Government \& Healthcare. KPMG, cutting through complexity. Retrieved from https://www.kpmg.de/docs/Education-in-China-201011.pdf

Michael, R. (2016). Education in China. World Education News \& Reviews. ASIA PACIFIC. Retrieved March 7, 2016 from http://wenr.wes.org/2016/03/education-in-china-2

MoE China. (2007). Ministerial Press Release on the Development of Compulsory Education and Literacy Education. Beijing. Retrieved from https://www.kpmg.de/docs/Education-in-China-201011.pdf

MoE China. (2012 a). Statistical newsletter of educational development in 2010 (in Chinese 2010 nian quanguo jiaoyu shiye fazhan tongji gongbao). Retrieved from http://www.moe.edu.cn/publicfiles/business/htmlfiles/moe/moe_633/201203/1326

MoE Chnia. (2001). Outlines of the reforms of basic education curriculum, article 7, July 2001, Beijing. Retrieved from http://www.moe.edu.cn/publicfiles/business/htmlfiles/moe/moe_2792/

MoE National Bureau of Statistics of China. (2004). China Statistical Yearbook, 2004. China Statistical Yearbooks Databas. Beijing: China Statistics Press. Retrieved from http://tongji.cnki.net/overseas/engnavi/YearBook.aspx?id=N2006010336\&floor $=\% 201$ 
MoE. (2013). Report on Progress towards EFA Goals in China Ministry of Education, China. Chinese National Commission for UNESCO.UNESCO International Research and Training Centre for Rural. Education (INRULED), Beijing China. Retrieved February 2013 from http://www.unescobkk.org/fileadmin/user_upload/efa/EFA_Coordinators_Mtg/13th_EF A_Coord_Mtg/China_EFA_Country_Report.pdf

Mucchielli, R. (1991). L'analyse de contenu des documents et des communications. (7è ed.). Collection Formation permanente en sciences humaines. Paris : Editions ESF.

Peng, W. J., McNess, E., Thomas, S., RongWu, X., Zhang, C., Li, Z. J., \& Tian, H. S. (2014). Emerging perceptions of teacher quality and teacher development in China. International Journal of Educational Development, 34, 77-89. http://dx.doi.org/10.1016/j.ijedudev.2013.04.005

People's Republic of China. (1982). Constitution of the People's Republic of China (1982).Peking: China. Retrieved from http://mjp.univ-perp.fr/constit/cn.htm

Sang, G., (2015). Barriers of Educational Development. [PowerPoint slides]. Reprinted from Lecture Notes entitled Education Systems, Policy and Management in China Faculty of Education of Beijing Normal University. International PhD/MA Program in Comparative Education (Education Management and Leadership).

Shangwu, S. (2006). Legislature Reviews Education Disparity. China Daily. Retrieved February 27, 2006 from http://www.chinadaily.com.cn/english/lt/lt_voaspecial.html

Statista. (n.d). Number of high school new entrolled students in China between 2004 and 2014 (in millions). The statistics Portal. Retrieved from https://www.statista.com/statistics/227033/number-of-high-school-registrations-in-china

Stewart, V. (2017). Chinese Innovations in Career and Technical Education. Asia Society 2017. Center for Global Education. Global cities education network. Retrieved from http://asiasociety.org/global-cities-education-network/chinese-innovations-career-and-te chnical-education

The World Bank Group. (2014). Gross enrolment ratio, secondary, both sexes (\%). UNESCO $\begin{array}{llll}\text { Institute for } & \text { Statistics. } & \text { Retrieved }\end{array}$ http://data.worldbank.org/indicator/SE.SEC.ENRR

Treasury Board Secretariat. (2001). Guide for the Development of Results-based Management and Accountability Frameworks. RMAF Guide. Retrieved from http://www.tbs-sct.gc.ca/cee/tools-outils/rmaf-cgrr/guide-eng.pdf

Tri, N. C. (2001). La privatisation de l'éducation en Chine. Perspectives chinoises, 1, 28-35.

UNESCO. (2016). Education for people and planet: Creating Sustainable Futures For All. Sustainable Development Goals. Global Education Monitoring Report. UNESCO Publishing. UNESCO Paris, France. Retrieved from 
http://unesdoc.unesco.org/images/0024/002457/245752e.pdf

United Nation Development Group (UNDG). (2011). Results-Based Management Handbook. Harmonizing RBM concepts and approaches for improved development results at country level. Retrieved from https://undg.org/wp-content/uploads/2014/06/UNDG-RBM-Handbook-

Université d'Avignon et des pays de Vaucluse (2013) : Méthodologie de la recherche documentaire : principes clés. Service Formation des Publics. Retrieved from Bu.univ-avignon.fr/wpcontent/uploads/2013/08/Methodo_documentaire.pdf

Wang, L. B. (2009). Basic Education in China. China: Zhejiang University Press.

Wang, R. (2005). Le financement de l'éducation dans l'ouest de la Chine. China Institute for Educational Finance Research, Norrag, (pp. 78-80). Peking University. Retrieved from http://www.norrag.org/fr/publications/norrag-news/online-version/special--theme-on-ed ucation-and-training-out-of-poverty-a-status-report/detail/le-financement-de-leducationdans-louest-de-la-chine.html.

Wang, X. (2014). L'éducation en Chine, entre tradition et modernisation, Colloque : L'éducation en Asie en 2014 : Quels enjeux mondiaux ? (Education in Asia in 2014: what global issues? (12-14 June 2014) Revue Internationale d'éducation de Sèvres, CIEP. Retrieved from https://ries.revues.org/3710

Xu, X., \& Mei, W. (2009). Educational Policies and Legislation in China. China: Zhejiang University Press.

Yang, M. (2009). Educational System in China. China: Zhejiang University Press.

Yixian, Z., \& Yanshu, Z. (2004). Rural Education: Progress and Problems. China's Education Blue Book, (pp. 150-175). Beijing: Higher Education Press.

\section{Copyright Disclaimer}

Copyright for this article is retained by the author(s), with first publication rights granted to the journal.

This is an open-access article distributed under the terms and conditions of the Creative Commons Attribution license (http://creativecommons.org/licenses/by/3.0/). 